\title{
Study on the Fire Behavior of Sandwich Wall Panels with GFRP Skins and a Wood-Web Core
}

\author{
Guangjun Sun, Chuting Wang and Lu Wang \\ College of Civil Engineering, Nanjing Tech University, Nanjing, 211816, China \\ *Corresponding Author: Lu Wang. Email: kevinlwang@njtech.edu.cn \\ Received: 05 August 2021 Accepted: 09 October 2021
}

\begin{abstract}
To investigate the temperature field and residual bearing capacity of the sandwich wall panels with GFRP skins and a wood-web core under a fire, three sandwich walls were tested. One of them was used for static load test and the other two for the one-side fire tests. Besides, temperature probe points were set on the sandwich walls to obtain the temperature distribution. Meanwhile, the model of the sandwich wall was established in the finite element software by the method of core material stiffness equivalent. The temperature distribution and performance reduction of materials were also considered. The residual bearing capacity of specimens after fire exposure were simulated considering the effects of web spacing, wall panel thickness and fire exposure time. Because the sandwich wall panels were stressed by eccentric compression after a fire, the residual compressive strength of the wall panel after the fire can be calculated through the eccentric loading analysis. Compared with the numerical results, it can be concluded that the effectiveness of calculation method of residual bearing capacity after fire exposure was proved.
\end{abstract}

\section{KEYWORDS}

Sandwich wall panels; fire behavior; fire test; finite element modeling; residual capacity

\section{Introduction}

Fibre reinforced polymer (FRP)-wood sandwich structural components have been widely adopted in the civil engineering due to their advantages of low energy consumption, corrosion resistance, fast construction, convenient maintenance and thermal insulation. FRP-wood sandwich structural components are usually formed by bonding the upper and lower high-strength skins and the middle light-weight core materials. The skins can bear tensile and compressive loads applied by bending moment, and the core materials can bear shear force [1,2]. To improve the bending strength and stiffness of flexural members, the glass fibre reinforced polymer (GFRP) webs are embedded in the core materials. The webs also can avoid the interfacial debonding failure [3].

In the past ten years, a number of experimental and theoretical studies on the mechanical properties of sandwich components at room temperature have been conducted. However, with the increase in the building fires in recent years, the fire resistance of sandwich components has caused the social extensive 
concern [4-6]. Bai et al. [7-10] studied the compressive strength of GFRP sheets and components under the temperature from $20^{\circ} \mathrm{C}$ to $300^{\circ} \mathrm{C}$. FRP materials were epoxy organic compounds, the resin began to soften when the temperature exceeded its glass transition temperature $(\mathrm{Tg})$, and some of the resins enter the thermal decomposition stage. When the ignition temperature exceeded $\mathrm{Tg}$, the resin was completely decomposed by heat, which resulting in the reduction of the strength and stiffness of FRP materials. Correia et al. [11] investigated the on-axis compression properties of pultruded GFRP I shapes under elevated temperature from $20^{\circ} \mathrm{C}$ to $250^{\circ} \mathrm{C}$. The results showed that the compressive strength at $250^{\circ} \mathrm{C}$ decreased sharply to $5 \%$ of that at room temperature. An analytical model was developed according to the Gompertz function to estimate the degradation of the compressive strength. Wong et al. [12] evaluated the compressive behavior of FRP channels under the temperatures from $20^{\circ} \mathrm{C}$ to $250^{\circ} \mathrm{C}$. The test results indicated that the ultimate compressive strengths at $120^{\circ} \mathrm{C}$ and $250^{\circ} \mathrm{C}$ were $26 \%$ and $8 \%$ of that at room temperature, respectively. Meanwhile, the axial stiffnesses were $45 \%$ and $29 \%$, respectively.

It is well known that wood is a kind of easily flammable material. The temperature rises, the physical and chemical changes occurred with the increase in temperature. Shen et al. [13] studied the changes of moisture with the temperature. The results showed that the moisture in the wood started to evaporated at $100^{\circ} \mathrm{C}$, and the moisture stopped to flow at $320^{\circ} \mathrm{C}$. Blasi et al. $[14,15]$ investigated the category and output of pyrolysis products. The effects of the heating rate, moisture pressure and inorganic substances on the pyrolysis reaction were analyzed. Zhang et al. [16] conducted the numerical study on the performance of wood with three surfaces exposing to fire. Compared with the test results, the accuracy of the proposed model was improved due to inputting the apparent thermal parameters of wood into the finite element software ANSYS. Janssens [17] proposed an analytical model to evaluate the residual strength considering dry density of the wood, moisture content of the wood, lignin content of the wood and char contraction.

However, most of the studies focused on the material properties subjected to a fire, while it is hardly to find some references to introduce the investigations on the fire resistance of sandwich components under fire exposure, which has become a serious lack of scientific basis for the use of such components in building structures. Therefore, the performance degradation mechanism subjected to a fire and residual bearing strength should be evaluated. This is the motivation of this study. In this paper, the GFRP web reinforced-Douglas fir sandwich wall panels were taken as an example for the one-side fire tests. Then, the variation distribution of the internal temperature field and residual bearing capacity were studied and analyzed, which provides a reference for the subsequent fire resistance design of sandwich components.

\section{Experimental Program}

\subsection{Specimen}

A total of three web sandwich specimens were produced in the tests. One of them was a control specimen, named Control, which was not subjected to a fire, while the other two specimens subject to a 60 min one-side fire, named HW110 and HW90, and then the residual strengths were tested after the fire exposure. For all the specimens, the length was $1800 \mathrm{~mm}$, the width was $350 \mathrm{~mm}$, the thickness of a skin was $5 \mathrm{~mm}$, the web thickness was $5 \mathrm{~mm}$ and the web spacing was $70 \mathrm{~mm}$. But the core thickness was different, the core thickness of Control and HW110 were $110 \mathrm{~mm}$, the core thickness of HW90 was $90 \mathrm{~mm}$. The Douglas fir was adopted as the core material. The component schematic is shown in Fig. 1. In this paper, the vacuum infusion molding process (VIMP) [1-3] is used for the component manufacturing process. The GFRP skins and webs were wrapped with $10 \mathrm{~mm}\left(0 / 90^{\circ}\right)$ glass fiber cloth, as shown in Fig. 2. The detailed specimen production process is as follows:

Step i: Douglas fir wood was cut according to the designed size along the grain direction. In the meantime, to completely and uniformly combine the resin with the core material, the Douglas fir wood should be grooved and punched before the resin was imported. 
Step ii: Douglas fir was wrapped with GFRP mats, and nails were driven into the core material by an air gun so that GFRP can be fixed on it.

Step iii: The specimens were wrapped by the vacuum bag. Then, the release cloth, flow guide cloth, and flow guide tube were installed.

Step iv: The vacuum bag was evacuated, and the unsaturated polyester resin was introduced to fully combine the fiber and core material.

Step v: After reaching the curing time (24 h), the specimen was cut according to the required dimension.

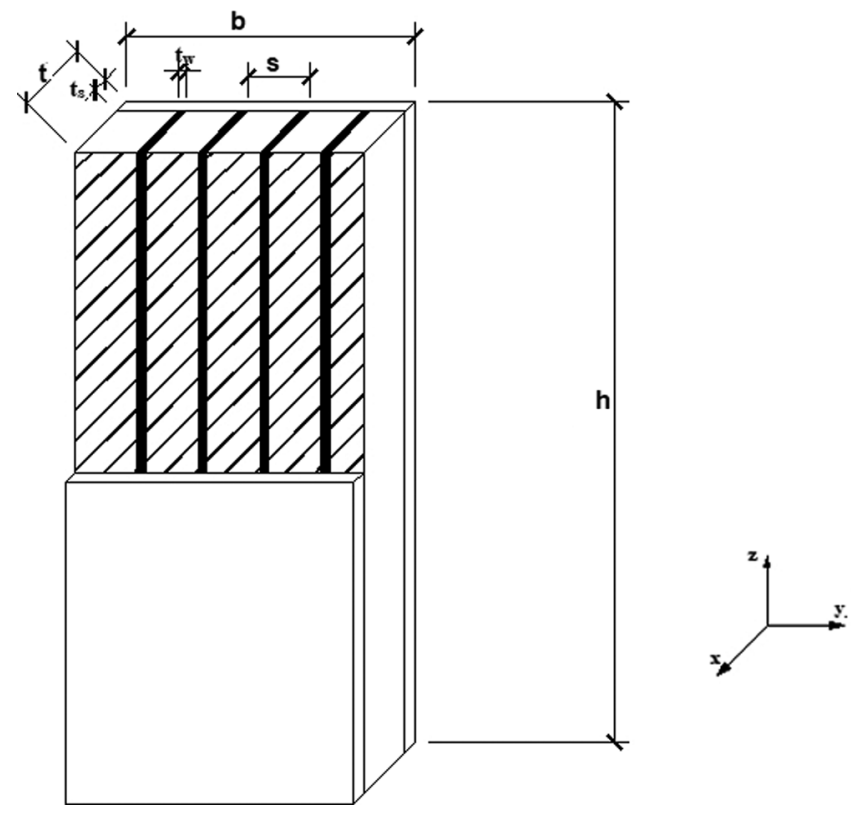

Figure 1: Component schematic

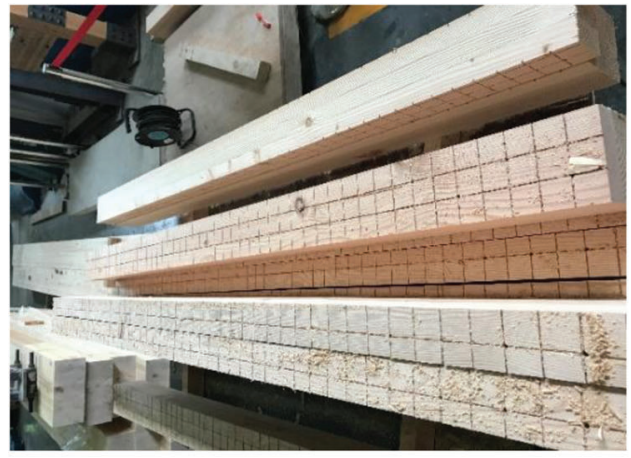

(a)

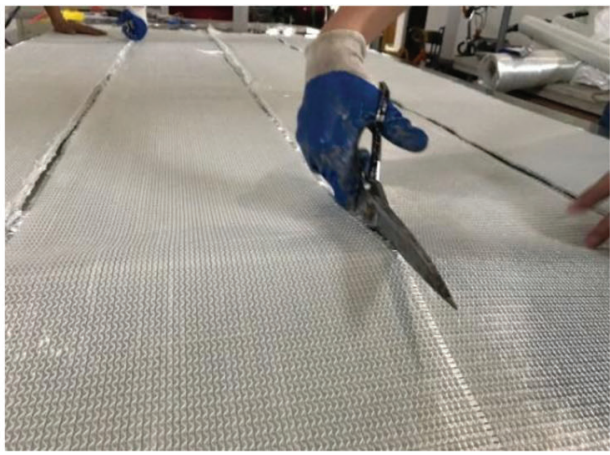

(b)

Figure 2: Continued 


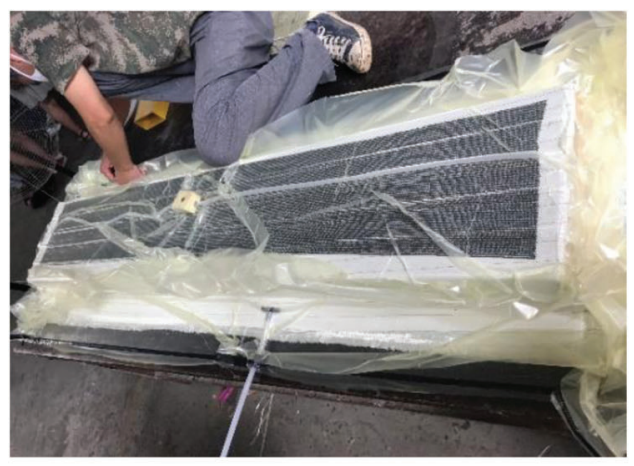

(c)

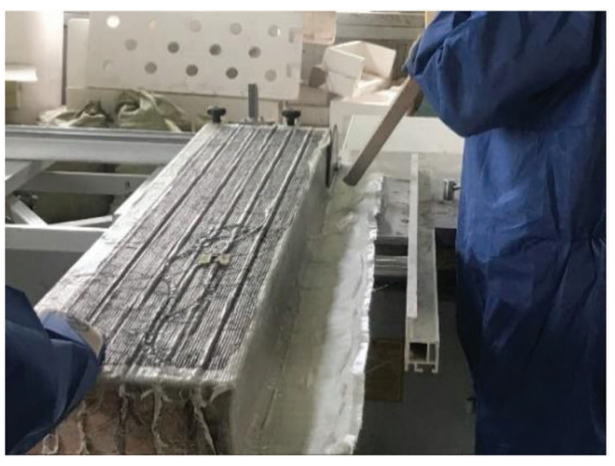

(d)

Figure 2: Specimen manufacture process. (a) Chamfering of Douglas fir timber (b) Cutting fiber cloth (c) Laying vacuum bag and guide cloth (d) Edge cutting and polishing

For specimens HW110 and HW90, the fire surface and the two sides were coated with ultra-thin fireproof coating. The brand of fireproof coating was Sika Pyroplast Wood T with topcoat. The coating thickness was $3 \mathrm{~mm}$. Meanwhile, to ensure the one-sided fire test, the aluminum silicate panels were installed on the side and backfire surface of specimens, as shown in Fig. 3.

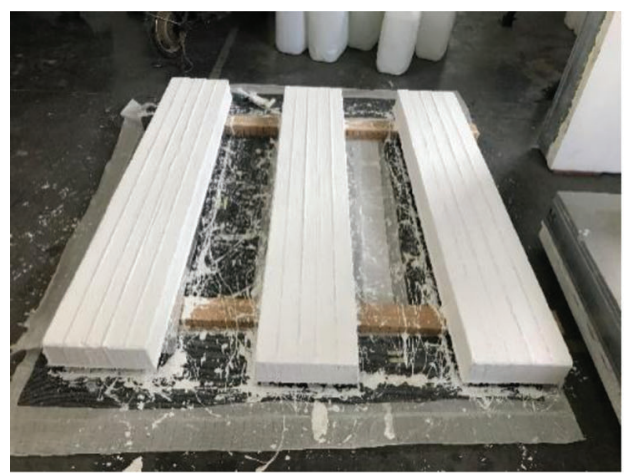

(a)

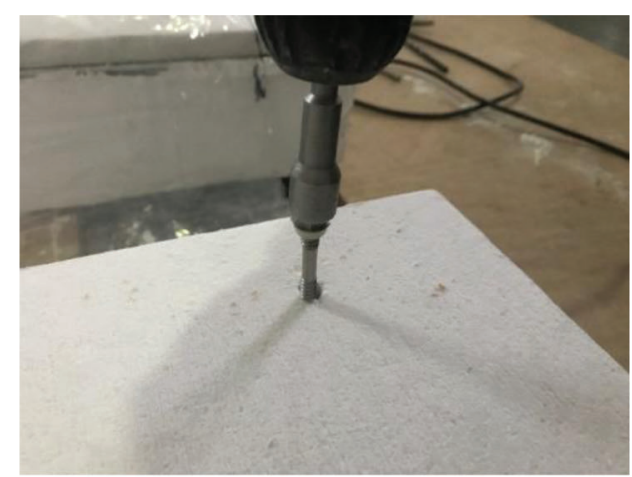

(b)

Figure 3: Fire prevention measures. (a) Apply fireproof paint (b) Installation of aluminum silicate board

The K-type thermocouples were arranged along the thickness of the wall panel to investigate the temperature distribution. The thermocouple depth was successively increased by $20 \mathrm{~mm}$. The positions are summarized in Tables 1 and 2. The schematic diagram of drilling is shown in Fig. 4.

Table 1: The K-type thermocouple position of specimen HW110

\begin{tabular}{llll}
\hline GFRP web & Hole depth $(\mathrm{mm})$ & Wood core & Hole depth $(\mathrm{mm})$ \\
\hline TW1 & 5 & T1 & 0 \\
TW2 & 10 & T2 & 5 \\
TW3 & 30 & T3 & 10 \\
TW4 & 50 & T4 & 30 \\
TW5 & 70 & T5 & 50 \\
\hline
\end{tabular}


JRM, 2022, vol.10, no.6

\begin{tabular}{llll}
\hline \multicolumn{2}{c}{ Table 1 (continued). } & & \\
\hline GFRP web & Hole depth $(\mathrm{mm})$ & Wood core & Hole depth(mm) \\
\hline TW6 & 90 & T6 & 70 \\
TW7 & 105 & T7 & 90 \\
- & - & T8 & 105 \\
- & - & T9 & 107 \\
\hline
\end{tabular}

Table 2: The K-type thermocouple position of specimen HW90

\begin{tabular}{llll}
\hline GFRP web & Hole depth $(\mathrm{mm})$ & Wood core & Hole depth $(\mathrm{mm})$ \\
\hline TW1 & 5 & T1 & 0 \\
TW2 & 10 & T2 & 5 \\
TW3 & 30 & T3 & 10 \\
TW4 & 50 & T4 & 30 \\
TW5 & 70 & T5 & 50 \\
TW6 & 85 & T6 & 70 \\
- & - & T7 & 85 \\
- & - & T8 & 88 \\
\hline
\end{tabular}

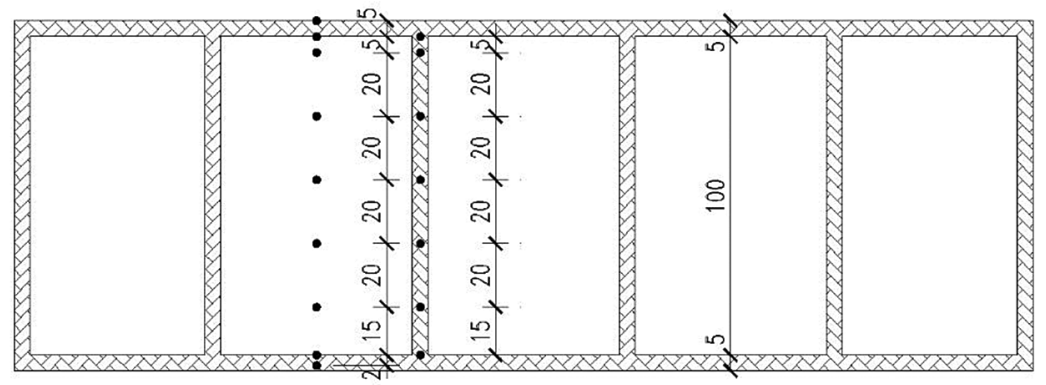

(a)

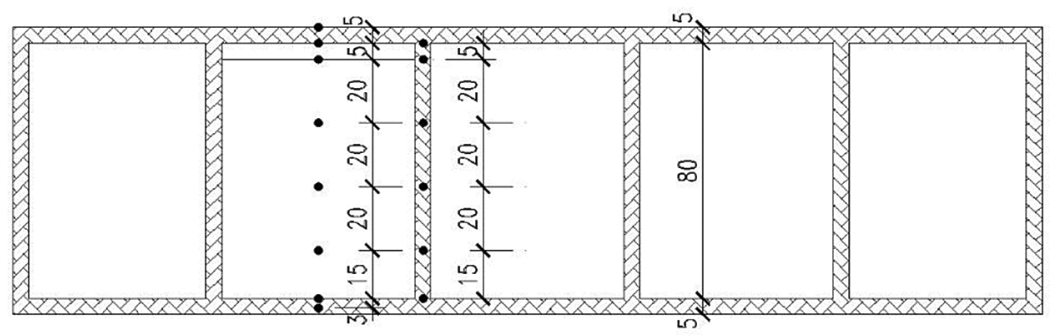

(b)

Figure 4: Schematic diagram of the thermocouple arrangement of the test pieces (a) HW110 thermocouple arrangement (b) HW90 thermocouple arrangement 


\subsection{Material Properties}

In this study, the tensile and compressive performance of GFRP skins (Fig. 5) and shear performance of Douglas fir (Fig. 6) were tested. Tensile and compressive strength tests, on the basis of GB/T 1447-2005 [18] and GB/T 1448-2005 [19], were conducted to determine the tensile strength, the tensile modulus, the compressive strength and the compressive modulus of GFRP skins. The loading rate was $2 \mathrm{~mm} / \mathrm{min}$ during tests. The material properties of GFRP skins are listed in Table 3. Wood is a typical anisotropic material, its physical and mechanical properties are significantly different in different directions. Hence, shear and compressive properties of Douglas fir were tested in multiple directions according to GB/T 1937-2009 [20] and GB/T 1935-2009 [21], respectively. The dimension of specimens were $20 \times 20 \times$ $30 \mathrm{~mm}$ for the compressive tests. The dimension of specimens were $35 \times 40 \times 20 \mathrm{~mm}$ for the shear tests. The loading rate was $2 \mathrm{~mm} / \mathrm{min}$. The material properties of wood are listed in Table 4 .

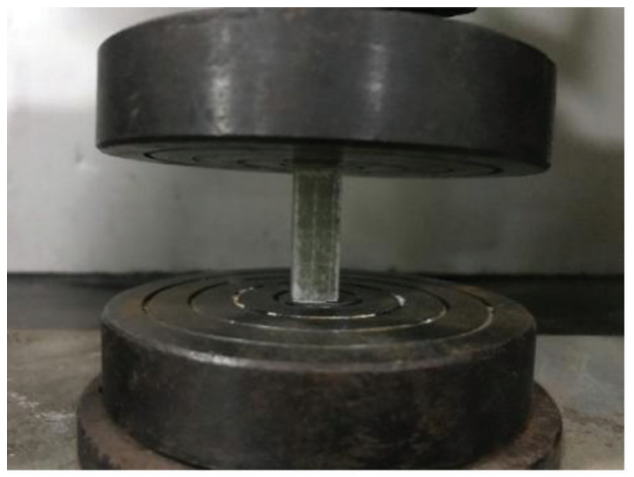

(a)

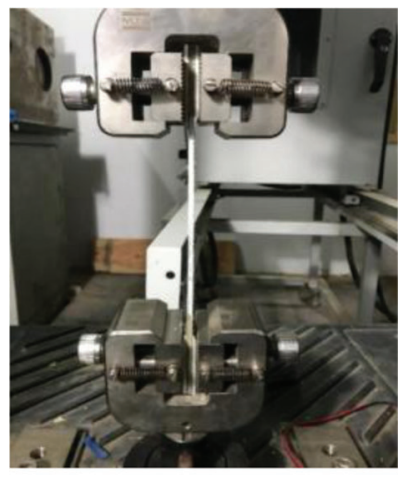

(b)

Figure 5: Material property testing of GFRP skins. (a) Compression test (b) Tensile test

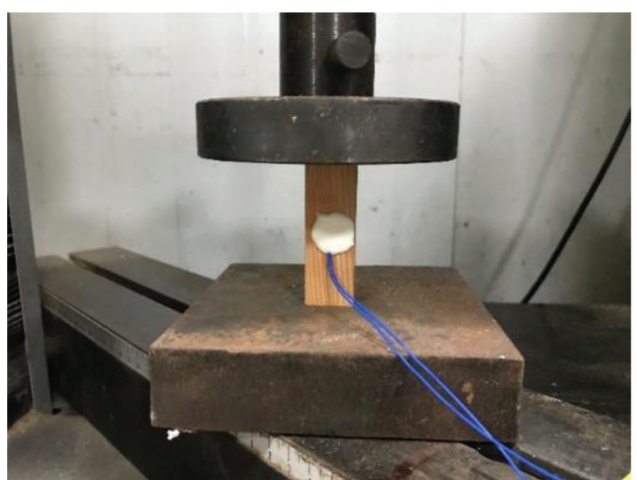

(a)

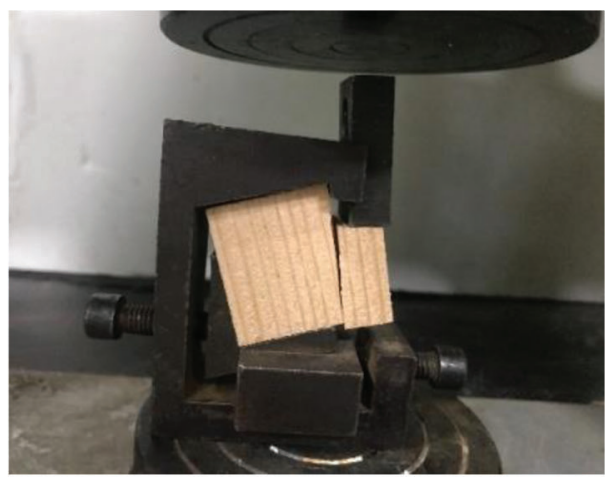

(b)

Figure 6: Material property testing of Douglas fir. (a) Compression test (b) Shear test

Table 3: Material properties of GFRP skins

\begin{tabular}{|c|c|c|c|c|c|c|c|c|}
\hline \multirow[t]{2}{*}{ Specimen } & \multicolumn{2}{|c|}{ Tensile strength } & \multicolumn{2}{|c|}{ Compressive strength } & \multicolumn{2}{|c|}{ Elastic modulus } & \multicolumn{2}{|c|}{ Poisson's ratio } \\
\hline & $\begin{array}{l}\text { Average } \\
\text { value } \\
(\mathrm{MPa})\end{array}$ & $\begin{array}{l}\text { Discrete } \\
\text { coefficient }\end{array}$ & $\begin{array}{l}\text { Average } \\
\text { value } \\
(\mathrm{MPa})\end{array}$ & $\begin{array}{l}\text { Discrete } \\
\text { coefficient }\end{array}$ & $\begin{array}{l}\text { Average } \\
\text { value } \\
(\mathrm{GPa})\end{array}$ & $\begin{array}{l}\text { Discrete } \\
\text { coefficient }\end{array}$ & $\begin{array}{l}\text { Average } \\
\text { value }\end{array}$ & $\begin{array}{l}\text { Discrete } \\
\text { coefficient }\end{array}$ \\
\hline $\begin{array}{l}\text { Standard } \\
\text { specimen }\end{array}$ & 220.3 & 0.0344 & 233.6 & 0.159 & 13.5 & 0.474 & 0.084 & 0.07 \\
\hline
\end{tabular}


Table 4: Material property of Douglas fir

\begin{tabular}{|c|c|c|c|c|c|c|c|}
\hline \multirow[t]{3}{*}{ Specimen } & \multicolumn{7}{|c|}{ Shear strength(MPa) } \\
\hline & \multicolumn{4}{|c|}{ Longitudinal section } & \multicolumn{3}{|c|}{ Cross-section } \\
\hline & \multicolumn{2}{|c|}{ Average value } & \multicolumn{2}{|c|}{ Standard deviation } & \multicolumn{2}{|c|}{ Average value } & Standard deviation \\
\hline Standard specimen & 2.628 & & 0.68 & & 4.943 & & \\
\hline \multirow[t]{3}{*}{ Specimen } & \multicolumn{7}{|c|}{ Compressive strength(MPa) } \\
\hline & \multicolumn{3}{|c|}{ Grain direction } & \multicolumn{2}{|c|}{ Cross-section } & \multicolumn{2}{|c|}{ Longitudinal section } \\
\hline & $\begin{array}{l}\text { Average } \\
\text { value }\end{array}$ & $\begin{array}{l}\text { Sta } \\
\text { der }\end{array}$ & & $\begin{array}{l}\text { Average } \\
\text { value }\end{array}$ & $\begin{array}{l}\text { Standard } \\
\text { deviation }\end{array}$ & $\begin{array}{l}\text { Average } \\
\text { value }\end{array}$ & $\begin{array}{l}\text { Standard } \\
\text { deviation }\end{array}$ \\
\hline Standard specimen & 43.005 & 5.6 & & 2.34 & 0.927 & 3.034 & 0.474 \\
\hline
\end{tabular}

\subsection{Test Set-Up}

The test set-up was MTS universal loading test machine, as shown in Fig. 7. The specimen was loaded via the distribution beam which moved through the fixed sliding track. The upper and lower ends of the specimens were supported by fixed ends. The transverse strain, longitudinal strain and lateral displacement at the mid-height of the wall panel were recorded, respectively. The DH3816 data logger was used to record the strain and displacement readings. The displacement control was adopted with the loading rate of $2 \mathrm{~mm} / \mathrm{min}$.

The fire tests were conducted at the Structural Fire Laboratory of Nanjing Tech University, China, as shown in Fig. 8. The large-scale furnace was built for full-scale fire tests on columns, walls, and floor elements. The heat was provided by twelve gas burners, with six burners on each side. The ISO-834 [22] standard temperature curve was adopted in the tests, which is expressed as follows:

$T=345 \lg (8 t+1)+T_{0}$

where $T$ is the temperature in the test furnace, in ${ }^{\circ} \mathrm{C} ; T_{0}$ is the temperature in the test furnace at the beginning of the test, in ${ }^{\circ} \mathrm{C} ; t$ is the time of the test in minutes.

\subsection{Static Test Results}

The ultimate load capacity of Specimen Control was $2446 \mathrm{kN}$. As shown in Fig. 9a, it can be found that the ultimate compressive displacement was $30 \mathrm{~mm}$. Due to the presence of the webs, the interaction between the skin and the core material increased so that the overall compressive deformation of the specimen was relatively small. Furthermore, the interfacial delamination was avoided. Fig. $9 \mathrm{~b}$ shows that the compressive load-strain relationship of the specimen is generally linear, and the longitudinal strain is much larger than the transverse strain. It can be concluded that the compressive strength of sandwich panels increased significantly due to the use of GFRP webs. Moreover, the compressive strength of wood core was also improved because of the confinement effect provided by skins and webs [2].

\subsection{Temperature Distribution}

The fire test was carried out for $60 \mathrm{~min}$. Fig. 10 shows the temperature distribution of the specimens during the tests. The slope of the heating curves of the specimens was relatively flat in the first $10 \mathrm{~min}$ but gradually increases between 10 and $20 \mathrm{~min}$. The reason was that the fire retardant coating provided a certain protective effect on the components in the early stage of the fire tests, which slows down the temperature rise of the specimens. When the fire retardant coating decomposed, the specimens were 
exposed to the flame on one side, hence, the temperature raised substantially. Meanwhile, when the temperature of any point on the backfire surface reaches $220^{\circ} \mathrm{C}$, it can be said that the fire insulation function of component was destroyed. During the fire tests, the temperature on the backfire surface of the grid was always within the safety range required.

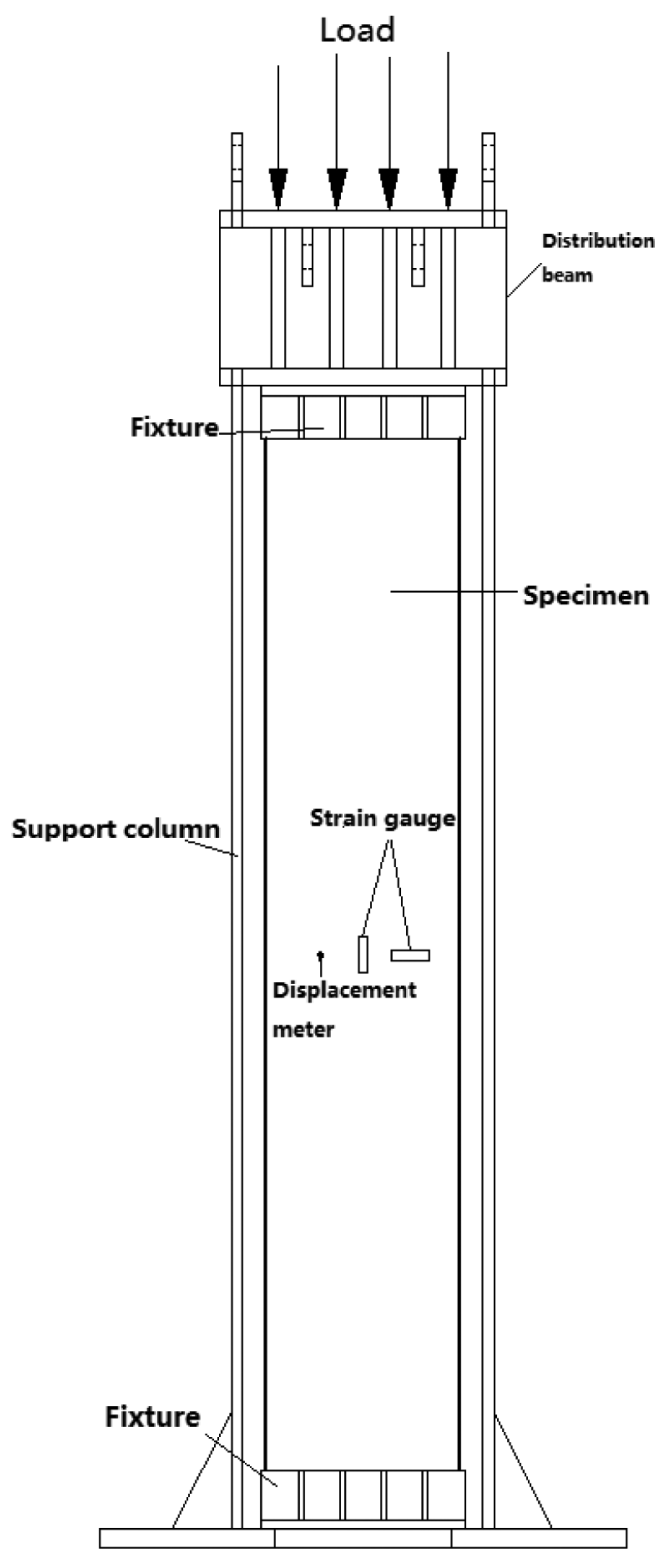

Figure 7: Loading schematic

\section{Numerical Investigations}

\subsection{FEM Modeling}

A FEM model was adopted based on the commercial finite element program, ABAQUS, to numerically study the behavior of the sandwich panels. The model consisted of two types of elements: four-node shell (S4R) for the skin, and eight-node reduced integration element (C3D8R) for the core. The boundary 
condition of panels is hinged support at one end and roller support at another. The two types of elements were assumed to have perfect bonding through the resin.

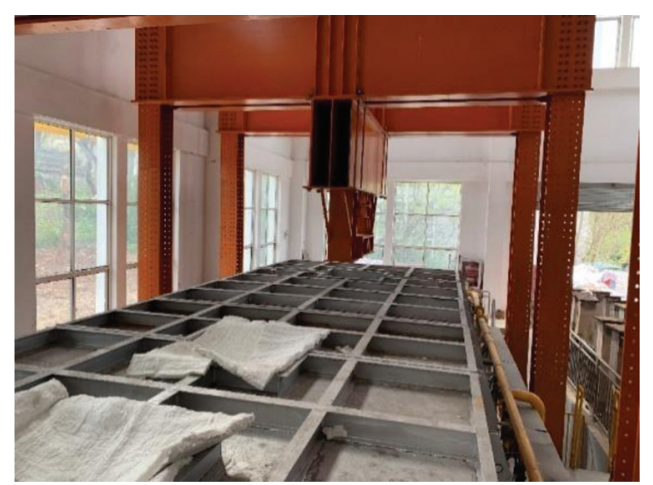

Figure 8: Fire test furnace

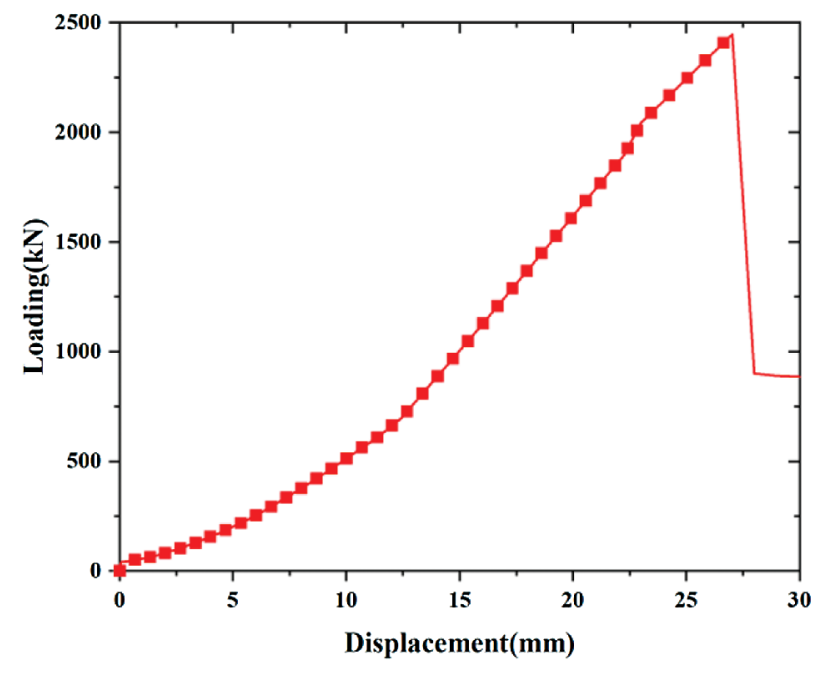

(a)

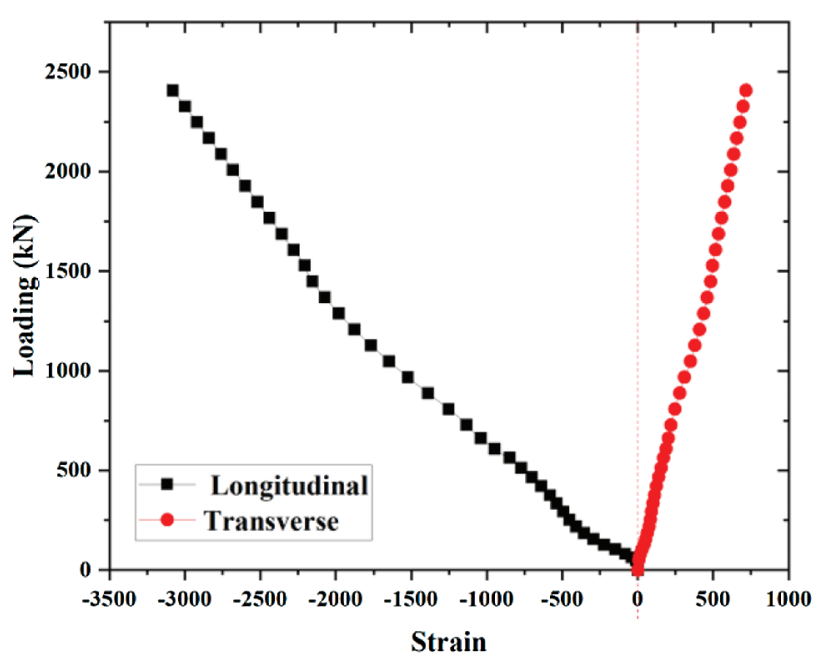

(b)

Figure 9: Static load test curve. (a) Load-displacement curve (b) Load-strain curve of wall panel

To simplify the numerical modeling, the equivalent modulus of the web reinforced core material was adopted [2]. Hence, the sandwich wall panels with GFRP skins and a wood-web core can be equivalent to a traditional sandwich panel with two skins and a homogeneous continuous core, as shown in Fig. 11. The equivalent core material was assumed as follows:

i) The core material was an elastoplastic material during the mechanical analysis process, regardless of the creep and relaxation behavior of the material.

ii) The core material was considered as orthotropic material considering the modulus equivalent processing.

The Hashin failure criterion was adopted for the skins, and the equivalent core material was applied to the maximum stress criterion. The formula for Hashin failure criterion is as follows [23]: 


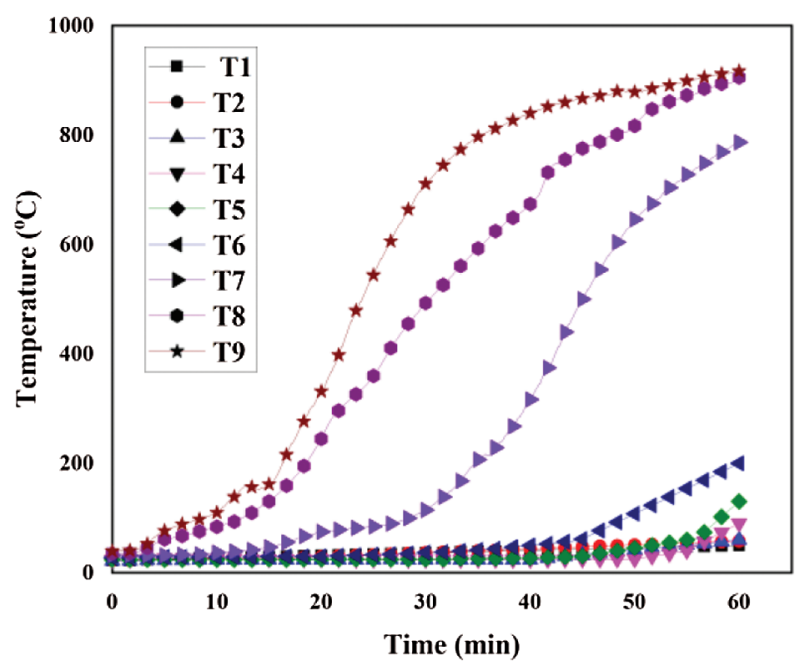

(a)

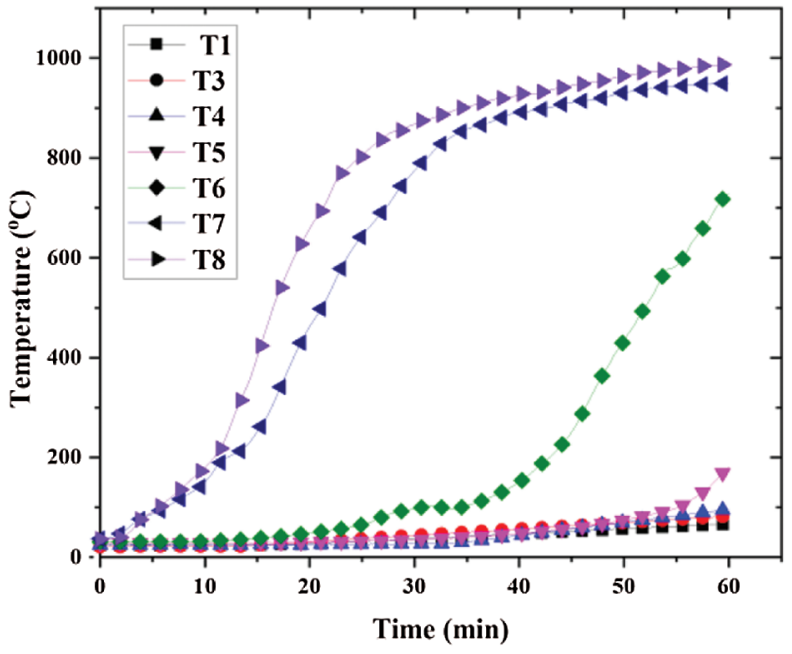

(c)

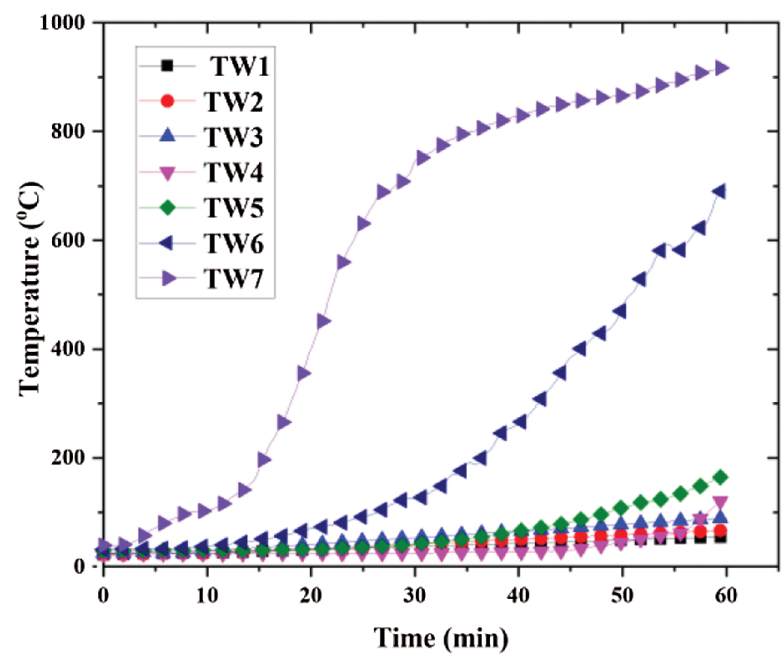

(b)

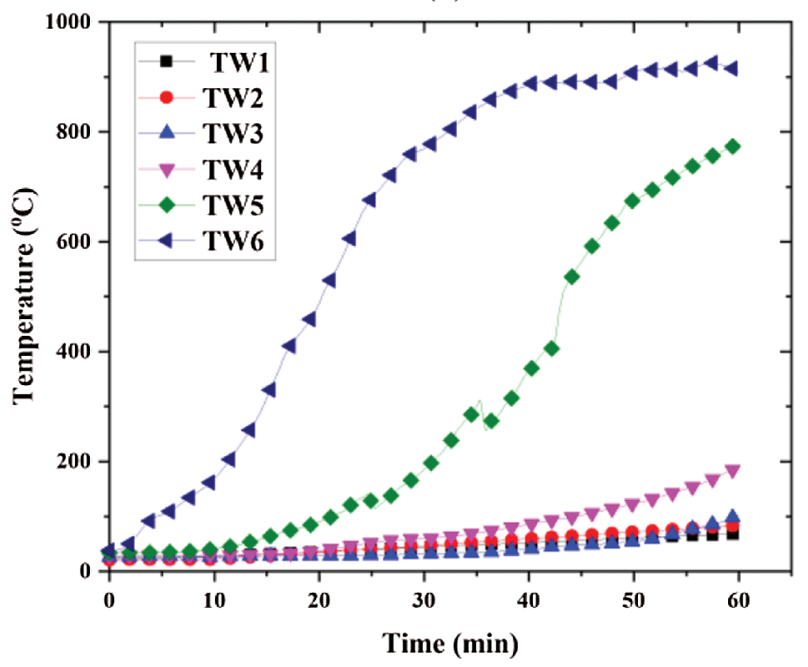

(d)

Figure 10: Temperature-time curve of specimens. (a) HW110 wood core temperature (b) HW110 web temperature (c) HW90 wood core temperature (d) HW90 web temperature

Fiber tensile failure:

$\left(\frac{\sigma_{1}}{X_{T}}\right)^{2}+\frac{\frac{\sigma_{12}^{2}}{2 G_{12}}+\frac{3}{4} \sigma_{12}^{4}}{\frac{S_{12}^{2}}{2 G_{12}}+\frac{3}{4} S_{12}^{4}}+\frac{\frac{\sigma_{13}^{2}}{2 G_{13}}+\frac{3}{4} \sigma_{13}^{4}}{\frac{S_{13}^{2}}{2 G_{13}}+\frac{3}{4} S_{13}^{4}} \geq 1$

Fiber compression failure:

$\left(\frac{\sigma_{1}}{X_{C}}\right)^{2} \geq 1$ 


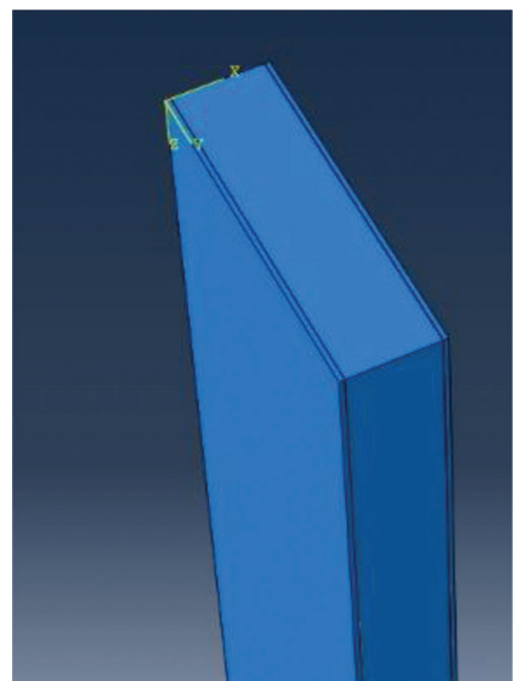

Figure 11: Model establishment

Fiber shear failure:

$\left(\frac{\sigma_{1}}{X_{C}}\right)^{2}+\frac{\frac{\sigma_{12}^{2}}{2 G_{12}}+\frac{3}{4} \sigma_{12}^{4}}{\frac{S_{12}^{2}}{2 G_{12}}+\frac{3}{4} S_{12}^{4}}+\frac{\frac{\sigma_{13}^{2}}{2 G_{13}}+\frac{3}{4} \sigma_{13}^{4}}{\frac{S_{13}^{2}}{2 G_{13}}+\frac{3}{4} S_{13}^{4}} \geq 1$

where $\sigma_{i}$ is the main direction stress; $\sigma_{i j}$ is the main direction shear stress; $X$ is the main direction strength; $S_{i j}$ is the shear strength; $G_{i j}$ is the shear modulus.

The residual post-fire bearing capacities of the sandwich wall panels were simulated. The tested temperature distributions of the specimens were input the numerical model. According to EN1995-1-2 [24], the property parameters of wood weakened with increasing temperature was set. For the performance reduction of GFRP skins, the model to calculate the temperature-dependent compressive strength and modulus was proposed by authors [25].

In this simulation, a total of 6 specimen models were established for simulation according to the three parameters, namely web spacing, wall panel thickness and fire exposure time. The parameters of the specimens are listed in Table 5. Specimen HWT110-30 was exposed to 30 min fire, and the dimension was identical with that of specimen HW110. Specimen HWT90-30 was exposed to 30 min fire, and the dimension was identical with that of specimen HW90.

Table 5: Detail of specimens

\begin{tabular}{|c|c|c|c|c|c|c|}
\hline \multirow[t]{2}{*}{ Specimen } & \multicolumn{3}{|c|}{ Specimen size } & \multirow[t]{2}{*}{$t_{s}(\mathrm{~mm})$} & \multirow[t]{2}{*}{$t_{w}(\mathrm{~mm})$} & \multirow[t]{2}{*}{$s(\mathrm{~mm})$} \\
\hline & $h(\mathrm{~mm})$ & $b(\mathrm{~mm})$ & $t(\mathrm{~mm})$ & & & \\
\hline HW110 & 1800 & 350 & 110 & 5 & 5 & 70 \\
\hline HWS110-50 & 1800 & 350 & 110 & 5 & 5 & 50 \\
\hline HWS110-105 & 1800 & 350 & 110 & 5 & 5 & 105 \\
\hline HWT110-30 & 1800 & 350 & 110 & 5 & 5 & 70 \\
\hline HW90 & 1800 & 350 & 90 & 5 & 5 & 70 \\
\hline HWT90-30 & 1800 & 350 & 90 & 5 & 5 & 70 \\
\hline
\end{tabular}

Note: $h$ is the panel height, $b$ is the panel width, $t$ is the core thickness, $t_{w}$ is the web thickness, $t_{s}$ is the skin thickness, and $s$ is the web spacing. 
To validate the accuracy of the proposed model, the ultimate strength of HW110 at room temperature was numerically calculated using the mentioned model. Fig. 12 shows the comparison between numerical and experimental results. The reason for the non-linear phase before the displacement of $13 \mathrm{~mm}$ in the test was that there was a pore inside the material of the component before compression, while the pores of the material were ignored during the numerical simulation. In the elastic region, the degree of coincidence was high.

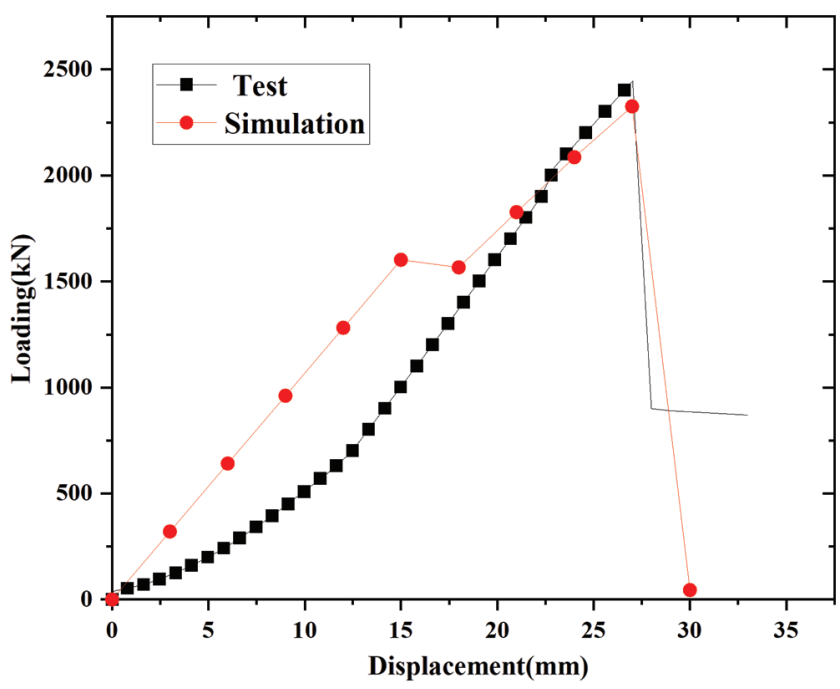

Figure 12: Load-displacement curve comparison

\subsection{Numerical Results}

Material properties and corresponding temperature distributions of HW110, HWS110-50, and HWS110105 were substituted into the simulation for reduction calculation, as shown in Fig. 13. It can be found that the bending degree of HW110 after the fire was greater than that of HWS110-105 but less than that of HWS110-50 since the web spacing of HWS110-105 was the smallest. The web was composed of GFRP, which the temperature sensitivity was more sensitive than wood. At the same time, after 60 min of fire load, the resin in the web basically evaporated, and the residual fiber cannot provide the residual bearing capacity, furthermore the wood was carbonized but does not decompose. A large number of incomplete carbonized sections were retained so that the stiffness and strength loss of HWS110-50 was the largest, which ultimately led to the highest bending degree.

Fig. 14 summarizes the load-displacement curves of the three simulated components. The residual strength of the wall panel after the fire also varied regularly with the number of webs. The number of the web was inversely proportional to the residual bearing capacity of wall panels after the fire. When the web spacing changed from 50 to $70 \mathrm{~mm}$, the residual bearing capacity of members was increased by about $20 \%$. However, when the spacing increased from 70 to $105 \mathrm{~mm}$, the residual bearing capacity was only increased by about $6.7 \%$. Therefore, the residual bearing capacity of the component can be effectively improved if the web spacing increased within a certain range.

HW110 and HW90 after 60 min fire tests were eccentrically compressed and destroyed. It can be found that HW90 was more prone to bending due to its wall thickness which was smaller than HW110, and the carbonization failure area on the fire side of it was larger than that of HW110. From the loaddisplacement curves in Fig. 15, HW90 lost strength due to the decrease in thickness under 60 min fire test, and its residual strength was $628.928 \mathrm{kN}$, which was about $14.6 \%$ lower than that of HW110 
$(736.41 \mathrm{kN})$. Therefore, the reduction in wall thickness had a greater impact on the residual strength of the component.

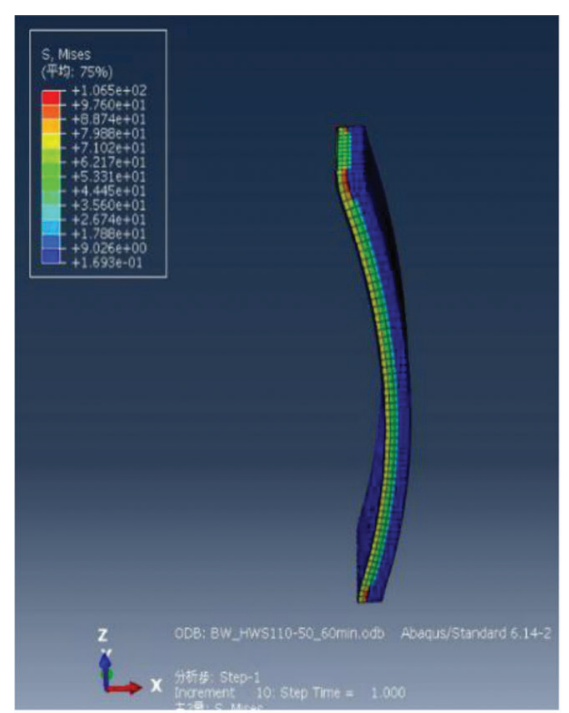

(a)

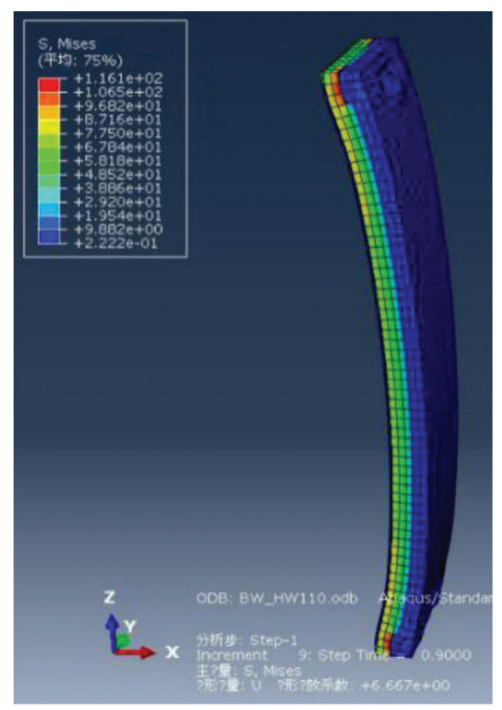

(b)

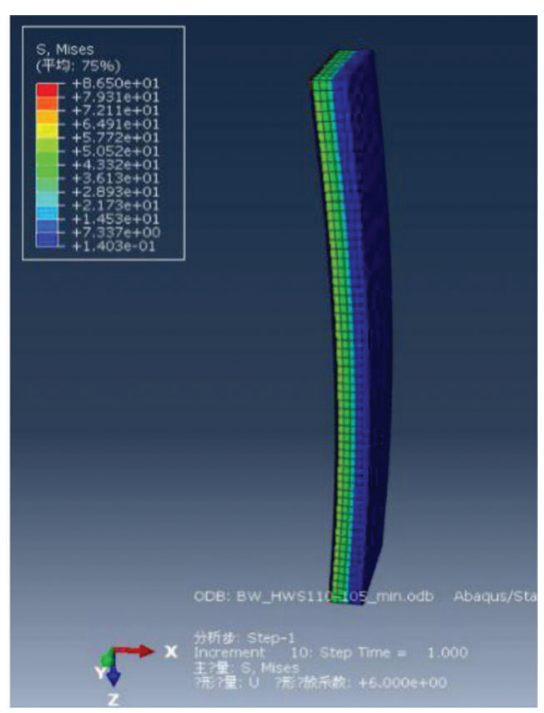

(c)

Figure 13: Post-fire compression analysis of HWS110-50, HW110, HWS110-105. (a) HWS110-50 (b) HW110 (c) HWS110-105

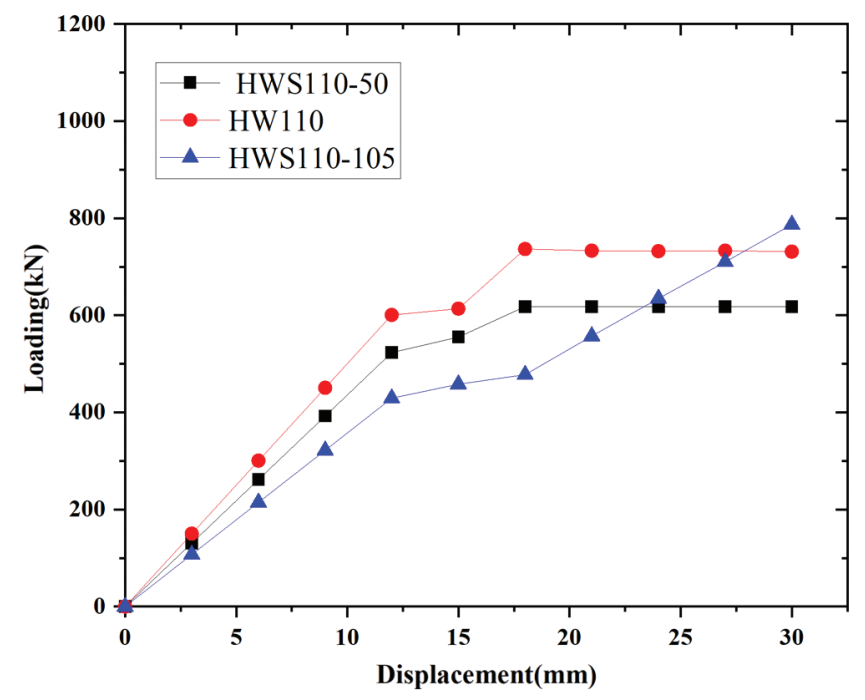

Figure 14: Post-fire load-displacement curves considering the effects of web spacing

Fig. 16 summarizes the load-displacement curves of the four components. It can be concluded that the residual bearing capacity of the $30 \mathrm{~min}$ fired component was significantly improved compared to the $60 \mathrm{~min}$ fired specimen. The residual compressive strength of HWT110-30 was $1210 \mathrm{kN}$, which was about $64.3 \%$ higher than that of HW110 $(736.41 \mathrm{kN})$. Compared with the residual compressive strength of HWT9030 and HWT90, the former had about $74.96 \%$ improvement. The reason was that the thickness of HW90 was reduced compared to that of HW110, and the distribution of internal temperature was more sensitive to the fire time. 


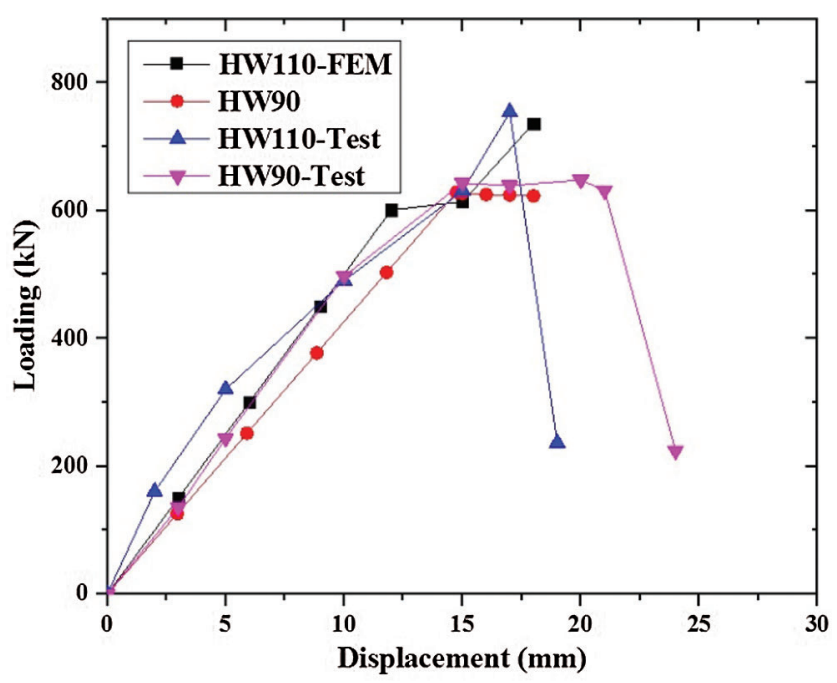

Figure 15: Post-fire load-displacement curves considering the effects of panel thickness

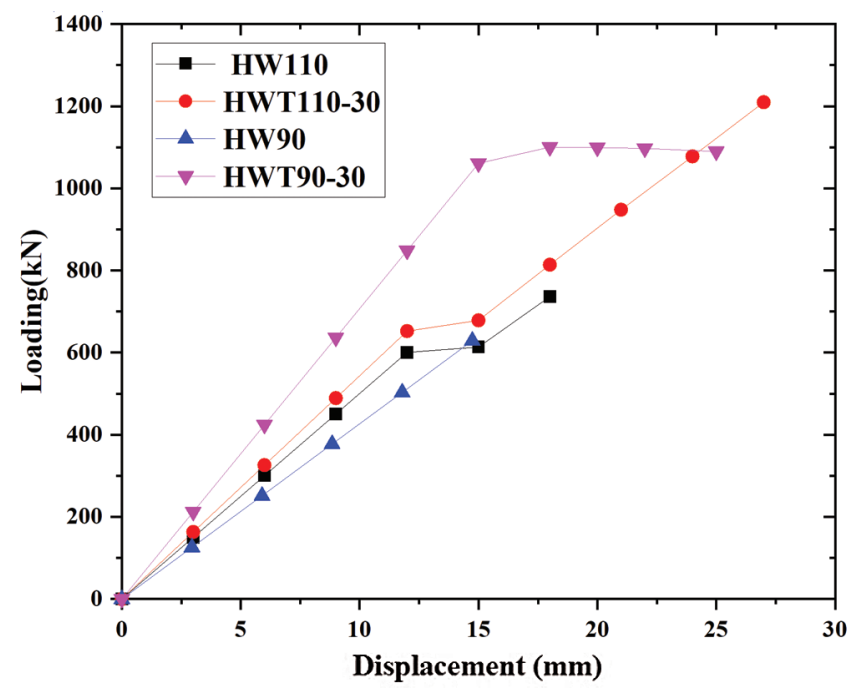

Figure 16: Post-fire load-displacement curves considering the effects of exposure time

Meanwhile, the ultimate bearing capacity of HW110 at room temperature is $2446 \mathrm{kN}$. After 30 min fire exposure, the residual bearing capacity was $1210 \mathrm{kN}$, and it was $628.928 \mathrm{kN}$ under 60 min fire exposure. Compared to the compressive bearing capacity of HW110 at room temperature, the compressive bearing capacities decreased by $50.5 \%$ and $74.3 \%$ after 30 and 60 min fire exposure, respectively. The conclusion can be drawn that components are obviously affected by the fire exposure time.

For sandwich wall panels after fire exposure, due to the different degree of material decomposition and carbonization on the fire surface and backfire surface, the loads applied to the fire-damaged components become eccentric compression. Therefore, the eccentric load analysis and calculation of were undergone. The residual compressive bearing capacity of the sandwich wall panel was theoretically calculated by analyzing the cross-section of the sandwich wall panel after the fire and the degrading of the corresponding material strength reduction. The theoretical and finite element calculation results are shown in Table 6. It showed that the results of theoretical calculation and finite element analysis results had a 
relatively good agreement, except HWS110-50. The reason for this phenomenon was that the finite element used the equivalent calculation of the GFRP webs, while all GFRP webs destroyed and their strengths were ignored in the theoretical calculation.

Table 6: Compared of finite element and theoretical calculation

\begin{tabular}{llll}
\hline Specimen number & FEM results $(\mathrm{kN})$ & Theoretical results $(\mathrm{kN})$ & Difference $(\%)$ \\
\hline HW110 & 814.11 & 736.41 & 9.5 \\
HWS110-50 & 766.46 & 618.022 & 19.34 \\
HWS110-105 & 861.3 & 789.83 & 8.23 \\
HWT110-30 & 1161.7 & 1210 & 3.99 \\
HW90 & 577.02 & 628.928 & 8.25 \\
HWT90-30 & 1060 & 1100.4 & 3.67 \\
\hline
\end{tabular}

\section{Conclusions}

In this paper, sandwich wall panels with GFRP skins and a wood-web core are taken as the research objection. The conclusions are summarized as follows:

The results show that GFRP skins and webs can provide the effective confinement to the wood core. Hence, the web reinforced sandwich wall panels can achieve much higher bearing strength.

The internal temperature-time variation rule of the sandwich structure was tested by using the internationally accepted ISO-834 standard heating curve and measured with the thermocouples. The result shows that although the thermal conductivity of GFRP webs and Douglas fir core materials are different, the temperature-time distribution of them is roughly the same.

The model of the sandwich wall panel was established by the finite element software. The residual bearing capacity after the fire of 6 components were analyzed taking web spacing, panel thickness and fire exposure time as parameters and combining with the temperature distribution law obtained in the fire tests. Specific conclusions are as follows:

(1) Improving the web spacing within a certain range can effectively increase the residual bearing capacity of members. When the web spacing was changed from 50 to $70 \mathrm{~mm}$, the residual bearing capacity of a member increased by about $20 \%$. However, the residual bearing capacity of them is only increased by about $6.7 \%$ when the web spacing changes from 70 to $105 \mathrm{~mm}$.

(2) When the thickness of the component is reduced by $18 \%$, the strength of it decreases by $14.6 \%$, and the reduction in the thickness of the wall panel has a large influence on the residual strength of the specimen.

(3) When the burning time is different, the residual strength of the component burning for 30 min is $74.96 \%$ higher than that of burning for $60 \mathrm{~min}$. By comparing the dead load specimens with those exposed to fire for 30 and $60 \mathrm{~min}$, the residual bearing capacity decreased by $50.5 \%$ and $74.3 \%$, respectively. It can be seen that the influence of fire exposure time is considerably important.

Funding Statement: The authors received no specific funding for this study.

Conflicts of Interest: The authors declare that they have no conflicts of interest to report regarding the present study. 


\section{References}

1. Wang, L., Liu, W. Q., Fang, H., Wan, L. (2015). Behavior of sandwich wall panels with GFRP face sheets and a foam-GFRP web core loaded under four-point bending. Journal of Composite Materials, 49(22), 2765-2778. DOI $10.1177 / 0021998314554124$.

2. Wang, L., Liu, W. Q., Wan, L., Fang, H., Hui, D. (2014). Mechanical performance of foam-filled lattice composite panels in four-point bending: Experimental investigation and analytical modeling. Composites Part B: Engineering, 67, 270-279. DOI 10.1016/j.compositesb.2014.07.003.

3. Zhang, L. F., Liu, W. Q., Wang, L., Ling, Z. B. (2019). Mechanical behavior and damage monitoring of pultruded wood-cored GFRP sandwich components. Composite Structures, 215, 502-520. DOI 10.1016/j. compstruct.2019.02.084.

4. Wang, X. K., Ma, Y. L., Liu, W. Q., Liang, R. F., Wang, L. (2017). Mode I interfacial fracture characterization of foam core sandwich materials at elevated temperatures. Journal of Reinforced Plastics and Composites, 36(14), 1009-1018. DOI 10.1177/0731684417699076.

5. Anjang, A., Chevali, V. S., Feih, S., Mouritz, A. P. (2016). Deterioration of the fire structural resistance of sandwich composite under tension due to water absorption. Composites Part A: Applied Science and Manufacturing, 87, 263-270. DOI 10.1016/j.compositesa.2016.05.008.

6. Bai, Y., Post, N., Lesko, J., Keller, T. (2008). Experimental investigation on temperature-dependent thermophysical and mechanical properties of pultruded GFRP composites. Thermochimica Acta, 469(1), 28-35. DOI 10.1016/j.tca.2008.01.002.

7. Bai, Y., Keller, T. (2009). Modeling of strength degradation for fiber-reinforced polymer composites in fire. Journal of Composite Materials, 43(21), 2371-85. DOI 10.1177/0021998309344642.

8. Bai, Y., Keller, T. (2009). Modeling of mechanical response of FRP composites in fire. Composites Part A: Applied Science and Manufacturing, 40(6-7), 731-738. DOI 10.1016/j.compositesa.2009.03.003.

9. Bai, Y., Vallée, T., Keller, T. (2008). Modeling of thermal responses for FRP composites under elevated and high temperatures. Composites Science and Technology, 68(1), 47-56. DOI 10.1016/j.compscitech.2007.05.039.

10. Bai, Y., Vallée, T., Keller, T. (2007). Modeling of thermo-physical properties for FRP composites under elevated and high temperature. Composites Sience and Technology, 67(15-16), 3098-3109. DOI 10.1016/j. compscitech.2007.04.019.

11. Correia, J. R., Gomes, M. M., Pires, J. M., Branco, F. A. (2013). Mechanical behaviour of pultruded glass fibre reinforced polymer composites at elevated temperature: Experiments and model assessment. Composite Structures, 98, 303-313. DOI 10.1016/j.compstruct.2012.10.051.

12. Wong, P. M. H., Davies, J. M., Wang, Y. C. (2004). An experimental and numerical study of the behaviour of glass fibre reinforced plastics (GRP) short columns at elevated temperatures. Composite Structures, 63(1), 33-43. DOI 10.1016/S0263-8223(03)00122-3.

13. Shen, D. K., Fang, M. X., Luo, Z. Y., Cen, K. F. (2007). Modeling pyrolysis of wet wood under external heat flux. Fire Safety Journal, 42(3), 210-217. DOI 10.1016/j.firesaf.2006.09.001.

14. Blasi, C. D. (1993). Analysis of convection and secondary reaction effects within porous solid fuels undergoing pyrolysis. Combustion Science and Technology, 90(5-6), 315-340. DOI 10.1080/00102209308907620.

15. Blasi, C. D. (2009). Combustion and gasification rates of lignocellulosic chars. Energy Combust, 35(2), 121-140. DOI 10.1016/j.pecs.2008.08.001.

16. Zhang, J., Liu, Z. H., Xu, Y. X. (2012). An experimental and numerical study on the charring rate of timber beams exposed to three-side fire. Science China Technological Sciences, 55(12), 3434-3444. DOI 10.1007/s11431-0124996-1.

17. Janssens, M. L. (2004). Modeling of the thermal degradation of structural wood members exposed to fire. 2nd Workshop on Structures in Fire, University of Canterbury, Christchurch, New Zealand. Fire and Materials, 28(2-4), 199-207. DOI 10.1002/(ISSN)1099-1018.

18. GB/T 1447-2005 (2005). Fiber reinforced plastics composites-Determination of tensile properties. Beijing, China. 
JRM, 2022, vol.10, no.6

19. GB/T 1448-2005 (2005). Fiber reinforced plastics composites-Determination of compressive properties. Beijing, China.

20. GB/T 1937-2009 (2009). Method of testing in shearing strength parallel to grain of wood. Beijing, China.

21. GB/T 1935-2009 (2009). Method of testing in compressive strength parallel to grain of wood. Beijing, China.

22. ISO 834-1 (1999). Fire-resistance tests-elements of building construction. International Organization for Standardization.

23. Wang, L., Liu, W. Q., Hui, D. (2014). Compression strength of hollow sandwich columns with GFRP skins and a paulownia wood core. Composites Part B: Engineering, 60, 495-506. DOI 10.1016/j.compositesb.2014.01.013.

24. Duarte, A. P. C., Sáez, A. D., Silvestre, N. (2017). Comparative study between XFEM and hashin damage criterion applied to failure of composites. Thin-Walled Structures, 115, 277-288. DOI 10.1016/j.tws.2017.02.020.

25. EN 1995-1-2:2004, Eurocode 5 (2004). Design of timber structures. Part1-2: General-structural fire design. Brussels. 